\title{
Infância e cidade: restrições e possibilidades
}

\author{
Childhood and city: restrictions and possibilities
}

Infancia y ciudad: restricciones y possibilidades

MANUEL JACINTO SARMENTO*

\begin{abstract}
RESUMO
A maior parte das crianças do mundo vive em cidades. Estas, cada vez mais marcadas por fenômenos de superpopulação, congestionamento de tráfego, aumento de indicadores de poluição, de insalubridade e de risco. E a população urbana não tem parado de aumentar. Porém, não são apenas esses os fatores que influenciam a vida das crianças na cidade. Como a investigação sociológica da infância tem vindo a assinalar, a vida das crianças exprime a complexidade das realidades sociais contemporâneas, podendo associar-se aos contextos urbanos, tanto fatores de restrição da cidadania da infância quanto fatores de possibilidade. A partir da caraterização desses fatores, procura-se, neste texto, fundamentar políticas públicas que potenciam o bem-estar das crianças e a afirmação dos seus direitos em contexto urbano.
\end{abstract}

Palavras-chave: Infância. Cidade. Cidadania. Direitos da criança. Sociologia da Infância.

\begin{abstract}
Most children in the world live in cities. The urban population has continued to increase, and with it, the number of children living in cities, increasingly marked by overpopulation, traffic congestion, indicators of pollution, unhealthiness and risk. However, it is not only these factors that influence the lives of the children in the city. As the sociological investigation of childhood has pointed out, the life of children expresses the complexity of contemporary social realities, which may be associated with both the restrictive factors of childhood citizenship and factors of possibility. Based on the characterization of these restriction and possibility factors, this text seeks to inform public policies that promote the well-being of children and the affirmation of their rights in an urban context.
\end{abstract}

Keywords: Childhood. Citizenship. Rights of the child. Sociology of Childhood.

\section{RESUMEN}

En su mayoría los niños y niñas del mundo viven en ciudades. La población no deja de aumentar y, con ella, aumenta también el número de infantes que habita en ciudades cada vez más marcadas por fenómenos como superpoblación, congestionamiento del tráfico, aumento en los indicadores de contaminación, insalubridad y riesgo. Sin embargo, no solo estas situaciones tienen influencia en la vida de los niños en la ciudad. Tal como la investigación sobre Sociología de la Infancia ha señalado, este hecho revela la complejidad de ciertas realidades sociales contemporáneas, pudiéndose asociar a los contextos urbanos relacionados tanto con factores de restricción de la ciudadanía de la infancia como de posibilidad. A partir de la caracterización de tales factores, en este texto se busca construir políticas públicas que potencien el bienestar de los niños y niñas y la afirmación de sus derechos en contexto urbano.

Palabras clave: Infancia. Ciudadanía. Derechos de niños y niñas. Sociología de la Infancia.

\footnotetext{
* Professor do Departamento de Ciências Sociais da Educação, Instituto de Educação. Membro do Centro de Investigação em Estudos da Criança na Universidade do Minho. Universidade do Minho, Portugal. <https://orcid.org/0000-0003-1532-2670>. E-mail: <sarmento.manuel@gmail.com>.
} 


\section{INTRODUÇÃO}

A crescente urbanização da sociedade contemporânea faz com que a maioria das crianças do mundo viva em cidades (UNICEF, 2012). Isso arrasta consigo um conjunto de problemas que estão associados às condições sociais de vida nos espaços urbanos, designadamente as relativas ao acesso à habitação condigna, salubridade, água potável, mobilidade, educação e espaços de lazer, bem como aspetos relacionados com a segurança rodoviária e com a proteção em face da violência social.

$\mathrm{O}$ crescimento da população urbana não significa que se tenham criado condições iguais para todos. Pelo contrário, esse crescimento é frequentemente, na sua raiz, a expressão do aumento das desigualdades sociais por efeito da concentração capitalista da propriedade no campo e do agravamento da pobreza em países do Sul Global. Especialmente os colocados em situação de sobre-exploração de recursos, arrastando multidões de migrantes que procuram a sobrevivência em cidades e países em que essa possibilidade lhes afigure como mais provável. Mas as desigualdades também se exprimem na própria organização da cidade em uma estratificação espacial que é correspondente à estratificação social. Espaços urbanos protegidos, seguros, de construção e equipamentos qualificados contrastam com espaços urbanos degradados, insalubres, desqualificados e frequentemente abandonados.

As desigualdades ao acesso à cidade e ao usufruto de condições de vida urbana são um elemento essencial na caraterização das restrições que atualmente se colocam nas cidades de concretização dos direitos sociais das crianças, a começar pelo "direito à cidade" (LEFÈBVRE, 2001). No entanto, as cidades não contêm apenas fatores de restrição de direitos; elas são, também, pelas suas caraterísticas espaciais e relacionais, contextos possíveis de potenciação dos direitos das crianças.

É nessa relação dialética entre restrição e possibilidade que se equaciona neste texto a condição da infância na cidade, a partir de uma perspetiva ancorada no trabalho teórico da Sociologia da Infância.

A investigação sociológica das crianças no espaço urbano conheceu recentemente, no plano internacional, uma profunda renovação, por efeito conjugado de três fatores: a) o desenvolvimento dos Childhood Studies e, em particular, da Sociologia da Infância, que trouxe para a agenda investigativa, sobretudo a partir dos últimos 30 anos, a condição social da infância e a compreensão da criança como ator nos mundos sociais de vida (JAMES; JENKS; PROUT, 1998; SIROTA, 2007; WIEVIORKA, 2008); b) a importância da cidade como topus investigativo nas Ciências Sociais, com a renovação da Sociologia urbana (SASSEN, 2005); c) a tematização da infância na cidade como reveladora social, isto é, a possibilidade de aceder a um conhecimento único sobre a sociedade, a partir do estudo das crianças e da análise das suas perceções, representações e perspetivas sobre a vida em comum.

Pondo em destaque o último dos fatores referidos - a situação da infância na cidade como reveladora social -, salienta-se, com C. Jenks (2005), que as cidades, como espaços sociais estruturados, com dispositivos de controle, são particularmente tornadas visíveis nas interdições formais e simbólicas feitas às crianças (de circulação, acesso, mobilidade, interação, práticas sociais) e nas transgressões feitas por elas. A vida delas em situação de rua é especialmente reveladora dessas transgressões e, por consequência, dos processos de interdição, divisão e controle do espaço urbano. Aliás, a pesquisa empírica dos meninos e meninas de rua constitui um importante domínio do conhecimento sobre a infância como categoria social. Isso porque esse estudo das crianças "à margem" é fortemente desafiador das conceções normativas hegemônicas na sociedade (SARMENTO; MARCHI; TREVISAN, 2018) e também na própria organização social no seu conjunto, na medida em que se exprimem relações familiares, comunitárias e de natureza institucional e política (MARCHI, 2007). Mas, na verdade, todas as crianças, que é suposto não estarem na rua, atualizam regras e rupturas com essas regras no cotidiano da vida urbana.

A investigação sociológica da infância tem posto em evidência a forma como as crianças transformam os espaços urbanos em "lugares", isto é, em contextos de interação revestidos de sentido e de emoções (CHRISTENSEN; O'BRIEN, 2003). Contextos esses que se apresentam ora como "espaços para crianças", onde é suposto estarem e nos quais circulam (bairros habitacionais, escolas, lugares de recreio), ora como "espaços das crianças" furtivos ao olhar adulto, produzidos na "ordem social das crianças" (FERREIRA, 2004) e nas suas culturas de pares infantis. Essa (re)institucionalização da infância na segunda modernidade (SARMENTO, 2006) passa também pela forte presença desses espaços para crianças no seu tempo de vida.

Entre a casa, a escola e os lugares do lazer, as crianças urbanas são transportadas, circulando entre "ilhas urbanas" (ZEIHER, 2003), no testemunho vivo da fragmentação das cidades modernas. Nesses espaços socialmente estratificados e divididos, com zonas exclusivas e zonas de exclusão, com condicionamentos e formas de ocupação restritos, a cidade contemporânea é dual (CASTELLS, 1989) em múltiplos sentidos.

A circulação (frequentemente em transporte público ou privado) entre os espaços institucionais, nas condições de (relativa) independência de mobilidade das crianças 
(O'BRIEN; JONES; SLOAN, 2000), faz das cidades lugares de ilusão, deslumbramento, mas também de desidentificação e de estranheza.

Representada como o habitante urbano "estrangeiro" de George Simmell, a criança dificilmente circula com a liberdade aparente do flanneur de Walter Benjamin. No entanto, o fascínio da cidade global (SASSEN, 2001), com as suas marcas, neóns, convites ao consumo, apelos dos múltiplos sinais dos centros de poder econômico, promove nas crianças a transfiguração imaginária do espaço urbano num lugar comunicacional, emergencial, polifônico e fantasista. De algum modo, esses espaços são sempre, para as crianças, as cidades invísíveis de Italo Calvino.

Procurar ouvir essa voz em que as crianças "revelam" (no sentido fotográfico do termo) as formas de vida da (na) cidade é um aspeto central para o conhecimento das crianças e das cidades. Nesse quadro, as políticas públicas urbanas para as crianças apresentam-se como incontornáveis, porque a cidade ocupa um lugar central no poder e na governança no contexto da globalização (FORTUNA, 1997; SASSEN, 2001; LE GALÈS, 2003) e porque é o espaço da inclusão ou exclusão na cidadania.

É exatamente porque a cidade tanto inclui como exclui que importa caraterizar os efeitos contraditórios e desiguais da vida urbana na configuração da infância, analisando tanto as oportunidades que oferece quanto os constrangimentos que opõe à cidadania da infância. Oportunidades que se exprimem em movimentos e ações orientados para a participação infantil, em cenários de proximidade e no quadro de iniciativas, como os orçamentos participativos com crianças, as Cidades Amigas das Crianças (UNICEF, 2004) ou a Cidade das Crianças (TONUCCI, 1991). Constrangimentos, porque a cidade "não é uma coisa" (FORTUNA, 1997) socialmente vivida e construída. Essa construção é, na sociedade de risco, potencialmente mais restritiva da autonomia das crianças, mais limitadora dos espaços, mais ameaçadora da segurança, mais indutora de formas globalizadas de colonização pelo consumo, mais potenciadora das desigualdades (nomeadamente, no acesso a espaços, a bens e a serviços urbanos).

Perceber, a partir dos olhos das crianças, essa tensão entre inclusão e exclusão, oportunidade e constrangimento, é um incontornável desafio investigativo com implicações na produção do conhecimento; mas também com uma dimensão de saber socialmente implicado, que não se deseja ocultar, centrada na análise da potenciação dos direitos da criança e na desconstrução crítica e política dos fatores de restrição que a cidade oferece.

Inicia-se por analisar estes últimos, para melhor se compreender a viabilidade dos primeiros fatores sobre cidadania da infância no espaço urbano.

\section{CidAde E RESTRIÇÃo dA CIDAdANIA DA INFÂNCIA}

Caraterizam-se os fatores de restrição da cidadania da infância em seis dimensões: domesticação, institucionalização, insularização, dualização, fragmentação e restrição da autonomia de mobilidade.

Domesticação é a designação adotada por Leverett (2011) para identificar o facto de um conjunto alargado de atividades de uso livre pelas crianças ter, no espaço urbano, sucessivamente vindo a ser controlado pelos adultos. Pode-se incluir nessas atividades o estar em conjunto com os pares, as atividades lúdicas e as brincadeiras, a relação com a natureza, as plantas e os animais. A estruturação urbana tende a identificar espaços circunscritos onde tudo isso tem lugar: os parques infantis; as empresas de lazer, dos videogames aos "parques de aventuras"; os serviços de organização de festas de aniversários; as seções dos restaurantes dedicadas às crianças etc.

A par da censura implícita da livre circulação das crianças pelas ruas, a configuração desses espaços organizados pelos adultos para crianças, por eles controlados e vigiados, constitui uma forte limitação à autonomia infantil e impõe pautas regulatórias dos comportamentos. Brincar nos parques infantis obedece a regras de utilização dos brinquedos e dispositivos (não é aceitável, por exemplo, subir o escorrega pelo lado do plano inclinado), e as empresas de serviços prescrevem os comportamentos a serem adotados (por exemplo, as festas de aniversário nas empresas de eventos seguem um ritual e uma rotina - envergar um colete identificador, brincar na cama elástica, sentar à mesa, soprar as velas e comer um bolo de chocolate etc.). E estes limitam a inventividade e a criatividade, padronizando as possibilidades comemorativas das crianças.

Essa domesticação depende da clausura dos espaços e é frequentemente realizada sob o pretexto de proteção das crianças. Com efeito, como afirma Leverett (2011, p. 15), "[...] a domesticação de espaços públicos e abertos resulta da intenção de pais e cuidadores de estabelecerem um balanço entre a segurança dos seus filhos e o desejo de lhes atribuírem um nível de independência adequada à sua infância". Na verdade, as preocupações securitárias tendem a sobrepor-se às intenções autonomizadoras. As crianças passam a realizar as suas atividades "livres", segundo padrões que materializam o controle. Sobretudo, quando essas atividades passam a ser dependentes do mercado de serviços para as crianças.

As cidades são um espaço privilegiado de expansão do mercado de produtos e serviços destinados à infância. A transformação em mercadoria das atividades inerentes às culturas infantis - como estar com outras crianças, brincar ou participar em comemorações e rituais configurantes 
das relações de pares - faz do processo de domesticação uma forma de indução infantil à organização econômica e social capitalista. Com efeito, o controle adulto de atividades infantis encontra aqui uma ocasião negocial que é largamente aproveitada pelas empresas dedicadas, em variadas áreas de negócio, do lazer à organização de eventos, passando pelas empresas de gamification.

A domesticação está fortemente ligada à institucionalização. Esta última expressão tem um duplo sentido: constituição da infância como um "fato social", por efeito da associação às crianças de um conjunto de ideias e conceções normativas; e colocação das crianças sob a égide de instituições sociais, isto é, de organizações destinadas ao cumprimento da missão de se ocupar das crianças e de as constituir de acordo com aquelas mesmas conceções normativas.

É na cidade que ocorre o processo de institucionalização na sua dupla acepção: por um lado, a normatividade infantil contemporânea em larga medida, decorrente de uma conceção urbana e ocidentalocêntrica da modernidade (SARMENTO; MARCHI; TREVISAN, 2018); e, por outro, a cidade, como espaço social onde proliferam as instituições para as crianças - escolas, jardins de infância, ateliês de tempos livres, clubes, lares e instituições de acolhimento etc. O processo de institucionalização incrementa as regras e os limites de ação das crianças no espaço.

Torna-se necessário, então, esclarecer por que a institucionalização é uma restrição à cidadania da infância. Considerando-se, nomeadamente, que a criação da escola pública se constituiu historicamente em um instrumento de cidadania, projetada para o futuro, pela ação de transmissão da cultura às jovens gerações, estas são, assim, supostamente preparadas para o exercício da sua condição cidadã quando adultas.

$\mathrm{O}$ viés que está contido nessa conceção, historicamente sedimentada e largamente pressuposta nas diferentes versões da teoria da socialização, de Durkheim a Bourdieu (para a respetiva crítica, CORSARO, 1997), reside no fato de, em nome da cidadania futura, retirar das crianças a condição cidadã. Essa tendência foi largamente denunciada pela pedagogia do princípio do século XX, de Dewey a Ferrière, mas isso não impediu que as instâncias socializadoras, e especialmente a escola, pudessem se constituir em torno de uma pedagogia autoritária e não participativa. Ora, a possibilidade de exercício da cidadania, presente e futura, reside na sua prática, isto é, no efeito conjugado de reconhecimento e de participação das crianças na vida em sociedade. A institucionalização da infância operou a transformação da criança em aluno (SARMENTO, 2011) e, por essa via, atribuiu-lhe uma condição de quase-cidadã ou de cidadã em processo, limitativa da possibilidade da sua plena afirmação como cidadã de pleno direito. E a cidade permitiu ampliar e consolidar esse processo.

As crianças, enquanto alunas na cidade, vivem uma organização peculiar do seu espaço-tempo. Elas circulam entre "instituições": da casa de família para a escola, da escola para o centro de "tempos livres" ou para o clube, destes para a casa de família. Essa circularidade entre espaços restritos, feita usualmente por transporte público ou privado (pelo menos nas cidades médias e grandes), faz com que as crianças naveguem entre ilhas no oceano urbano. É precisamente a metáfora da ilha que Zeiher (2003) utiliza para dar conta dessa experiência fragmentária do espaço urbano. Insularização é a condição da vida confinada das crianças. O espaço intersticial entre as instituições, sobretudo no caso das situações de controle o mais restritivo da mobilidade, constitui-se para as crianças em um grande desconhecido. Por consequência, a sua experiência, nesses casos, é bastante limitada a respeito da vida urbana e das suas possibilidades. A participação cidadã pelas crianças, na representação, definição e proposta de configuração do espaço urbano, fica, nessas circunstâncias, fortemente condicionada. Desse modo, o afastamento espacial das crianças, ou a sua restrição, é também um afastamento da possibilidade de produção pela criança de uma autoconsciência como ser da cidade e como interveniente na vida em comum.

O efeito de insularização é ampliado pelos modos como a cidade se constitui diferenciadamente e se desenvolve como espaço dual. O desenvolvimento urbano não foi nunca indistinto das lógicas de apropriação do espaço pelas classes dominantes e nem pelas suas lógicas de acumulação e apropriação de recursos, bem como de disponibilização para as relações de troca (HARVEY, 2009). As cidades foram organizadas em espaços exclusivos e espaços de exclusão, com áreas de transição entre ambos. Essa realidade é dinâmica, e as cidades sofrem transformações por períodos mais ou menos dilatados no tempo. Por exemplo, as áreas centrais das cidades, por décadas abandonadas pelas classes dominantes e deixadas para habitação, frequentemente degradadas, de populações mais empobrecidas (as inner cities), sofrem contemporaneamente um movimento de requalificação. Processo este arrastado ou não pelo turismo de massas, com efeitos muito significativos no encarecimento da habitação e na consecutiva expulsão das populações tradicionais para zonas periféricas. Assim, ocorre nesses locais a substituição por novas populações, endinheiradas, no quadro de uma generalizada gentrificação. Esse fenômeno, impressionantemente vivido na atualidade nas principais cidades portuguesas, à semelhança de muitas outras no mundo inteiro, não foi ainda suficientemente estudado no que respeita ao seu impacto na infância. Porém, ele é a prova do 
processo de dualização social e de fragmentação da vida urbana.

A dualização oferece oportunidades desiguais às crianças, provocando uma restrição da cidadania por não observação dos direitos sociais. As crianças pobres, que vivem nas periferias mais ou menos desqualificadas, confinadas aos "bairros sociais" ou às favelas, onde passam a totalidade do seu tempo, são as mais afetadas pela dualização social do espaço. Mas são elas, em consequência da sua situação de pobreza e de exclusão, as que menos oportunidades têm de usufruto da experiência propiciada pela cidade, dos espetáculos à frequência de monumentos e sítios, das visitas a museus e bibliotecas aos parques. Isso não significa, bem entendido, que as crianças pobres não tenham uma experiência rica na construção das suas culturas (nomeadamente pela construção e uso de brinquedos populares e artesanais, pela maior liberdade de movimento e de expressão cultural, pela afirmação das formas peculiares das suas culturas infantis, como a investigação sobre as culturas das crianças das classes populares largamente documentadas) (ARENHART, 2016; BARRA, 2016). Significa, outrossim, que a organização dual do espaço urbano se associa à estratificação social e é desta uma componente indissociável.

Mas a dualização afeta todas as crianças, ainda que de modo desigual, por meio de uma experiência fragmentária da cidade. Os espaços urbanos emergem como locus cheios de interdições, de receios e medos inculcados, de destinos indesejados, par a par com lugares de atração e apego, dos shoppings aos estádios de futebol, ambientes desejados que incendeiam a imaginação e, frequentemente, inculcam precocemente uma cultura de consumo. Essa fragmentação elimina a possibilidade de uma experiência verdadeiramente democrática do uso do espaço. Como afirma J. Machado Pais, "[...] o espaço é muito mais do que a projeção de uma representação intelectual. É uma produção feita de movimentos, gestos, cumplicidades. $\mathrm{O}$ mesmo se pode pensar da cidadania. A cidadania apenas se cumpre quando localmente é exercida" (2010, p. 130-131).

\section{A FRAGMENTAÇÃo dA CIDAdE É FONTE DA RESTRIÇÃO DA CIDADANIA LOCAL}

Finalmente, entre os fatores de restrição, a limitação da autonomia de mobilidade das crianças constitui-se em um dos temas mais significativos. Tem sido objeto de múltiplos estudos e é continuamente monitorizado e documentado pela investigação internacional sobre infância e mobilidade (SHAW et al., 2015).

Um dos principais fatores de limitação da autonomia de mobilidade é a automovilização das cidades. O crescimento exponencial do parque automóvel retirou as crianças das ruas, para além de outros efeitos funestos, como o aumento das emissões de gases poluentes, o incremento do ruído urbano, a transformação de parques e lugares naturais em parques de estacionamento, os engarrafamentos nos acessos e principais vias de circulação nas cidades etc. Tudo isso, além do mais grave de todos os efeitos: a sinistralidade urbana provocada por acidentes rodoviários.

A automovilização da cidade tem efeitos paradoxais: por um lado, permite, em teoria, percorrer maiores espaços em menos tempo e com menos esforço físico; por outro, diminui o conhecimento efetivo da cidade, a exploração dos espaços e tem graves consequências na restrição da circulação pedestre, com diminuição do equilíbrio propiciado pelo exercício físico.

Um dos efeitos mais funestos da automovilização da cidade é a desumanização de muitas ruas e avenidas. As crianças e as pessoas idosas são as primeiras a serem retiradas da circulação a pé, quer pelos riscos (reais e projetados) que isso implica, quer pela inexistência de condições de conforto na circulação e atravessamento das ruas. Por isso mesmo, a inversão dessa situação é uma das prioridades de política pública para a conversão das cidades em espaços humanizados (TONUCCI, 2001).

Os efeitos da limitação da autonomia de mobilidade nas crianças são, em síntese, múltiplos: afetam o conhecimento do espaço urbano e o acesso à experiência do seu usufruto; têm resultados profundamente negativos na corporeidade infantil e estão associados a fatores como o aumento da obesidade e do peso infantis, e o desenvolvimento de doenças decorrentes de reduzido exercício físico; limitam o contato entre gerações, ao retirarem da circulação pública sobretudo os cidadãos mais novos e os mais velhos; exponenciam os fatores de insularização e fragmentação da experiência urbana já atrás assinalados.

\section{CIDAde E POTENCIAÇÃo dA CIDAdANIA DA INFÂNCIA}

Mas a cidade também pode potenciar a cidadania da infância. Ela é, por definição, um espaço de interações sociais múltiplas, onde as funções essenciais da vida individual e coletiva têm lugar. $O$ que determina a possibilidade de potenciação da cidadania é o desenvolvimento de políticas urbanas que permitam a concretização do reconhecimento e da participação das crianças. Políticas orientadas para o bem-estar das crianças e para a cidadania infantil podem potenciar os fatores favoráveis a seguir referenciados: a personalização, a affordance, a experiência, a intergeracionalidade, a participação e a urbanidade. 
A personalização ocorre sempre que se atribui ao espaço um valor simbólico específico. As crianças continuamente investem de emoção e significado os espaços que habitam, transformam-nos em lugares, no sentido em que lhe atribuem um valor próprio, repleto de memórias, sentimentos e significações íntimas. O conhecimento e a perceção do espaço realizam-se no plano biográfico de cada criança e incorporam-se na sua própria personalidade (CHRISTENSEN; O'BRIEN, 2003). A cidade está repleta de pontos assinalados pelas crianças nos seus percursos (sejam eles mais ou menos extensos, sejam autônomos) e emerge nos desenhos que elas fazem: os parques infantis onde brincam, a cor das casas, de si próprias ou dos amigos, a torre do castelo ou do palácio que assinala a presença da História na paisagem urbana, os letreiros dos shoppings ou a imensidão dos hospitais que porventura um dia visitaram. Tudo isso se integra à identidade pessoal da criança e está profundamente imbrincado com a sua constituição como pessoa e como sujeito. Na medida em que está territorializada e incluída num espaço urbano específico, essa identidade é transindividual e constitui a criança como sujeito enraizado no lugar.

Esse processo de personalização está associado a escolhas que a criança faz ou que se lhe impõem no seu roteiro pela cidade. Estabelecem-se, desse modo, entre a criança e a cidade, determinados pontos de contato, de atração ou de repulsa, de apego ou de rejeição que são profundamente individualizados e que, no seu conjunto, compõem um mapa individual de afetos e desafetos. Ao estabelecer esse mapa, a criança tem possibilidade de construir as suas opções.

O conceito de affordance deriva da Psicologia Social e refere-se às propriedades dos objetos ou do contexto ambiental que podem ser apropriadas e percebidas pelo sujeito. Ele é útil para se compreender esse aspeto do vínculo da criança como o espaço urbano. Na sua aplicação às relações que as crianças estabelecem com o meio ambiente e, em especial, com a cidade, a affordance positiva (HEFT, 1988) refere-se às propriedades dos espaços, edifícios, mobiliário urbano, equipamentos etc. que podem ser percebidas pelas crianças de modo que elas estabeleçam com esses espaços uma relação de empatia. $\mathrm{O}$ conceito (sem tradução clara em português) visa a reportar a oportunidade que os objetos ou o meio ambiente oferecem para a construção da personalidade e das ações do sujeito. Favorece o entendimento das relações transacionais entre o sujeito e os elementos materiais que o rodeiam, de tal modo que, na interação entre um e outros, ocorrem mudanças e transformações em ambos.

O espaço urbano e os seus elementos constitutivos (edifícios, ruas, jardins, veículos, equipamentos etc.) oferecem diferentes oportunidades percetivas a crianças e adultos. São, portanto, distintas as affordances desses objetos ou espaços para uns e outros. Um pequeno muro divisório no jardim de uma cidade pode ter uma utilidade funcional para os adultos e outra para as crianças. Para estas, pode ser o lugar onde se sentam com os amigos, o obstáculo a ultrapassar com um salto do skate ou a barra fixa onde exercitam atividades de equilibrismo. Um fontanário ou um espaço com água pode ser para os adultos um referente patrimonial ou decorativo da cidade, mas também pode ser para as crianças o oceano onde se lançam barcos de papel ou, no calor, a piscina improvisada aí colocada à mão de semear.

As propriedades dos objetos dão origem a diferentes perceções, e estas, por sua vez, podem influenciar esses mesmos objetos, promovendo transformações e mudanças que garantam a sua apropriação mais positiva. As inscrições nas árvores, os grafites, as pinturas com giz no chão da calçada e outras marcas realizadas pelas crianças (e, sobretudo, mas numa outra escala, pelos jovens writers) são modos de apropriação e transformação espacial da cidade que, algo paradoxalmente, exprimem um modo de expressão cidadã. Longe de serem um mero ato de vandalismo, as inscrições na cidade podem ser identificadas como uma forma de apropriação corporal e linguística do espaço urbano, a marcação do território, dentro da lógica de afirmação de uma cidadania diferenciada e alternativa. Como afirma J. Teixeira Lopes (2007, p. 80), a relação com a cidade pode muito ser pensada e projetada por meio de "[...] identificações [que] vão sendo forjadas de forma dinâmica, dialógica e multifacetada, em permanente relação e aprendizagem pela experiência [o que constitui] uma outra forma, afinal, de fazer lugar, ocupando os espaços vazios da cidadania".

Se o espaço urbano potencia affordances positivas, elas são tanto mais alargadas quanto maiores forem as oportunidades de autonomia de mobilidade na cidade (LOPES; CARLOS NETO, 2014). O que vem acentuar, uma vez mais, a importância das políticas urbanísticas que favoreçam a circulação pedonal das crianças pelo território urbano.

Essa circulação é o que favorece a "experiência", no sentido benjaminiano do termo. Ao longo da produção teórica de Walter Benjamin, o conceito de experiência foi sendo desenvolvido, incorporando diferentes cambiantes e acepções. Numa expressão formulada pelo autor, define-se a experiência como "a multiplicidade unitária e contínua do conhecimento.” (BENJAMIN, 1971, p. 111). A riqueza da experiência está na capacidade humana de se relacionar com o real, aprendendo-o e expondo-o por meio da linguagem e, nesse ato, incorporando o conhecimento historicamente sedimentado com a assimilação do novo. Em sua crítica à pobreza da experiência da 
sociedade capitalista, Benjamin (1971) refere-se às formas estereotipadas e gastas com que a mesmidade da mercadoria e das suas estratégias de apresentação tende a impor gostos comuns e vivências marcadas pelo atrofiamento devido ao desenraizamento e à alienação. $\mathrm{O}$ autor evoca as sociedades tradicionais e as crianças como capazes da experiência autêntica, isto é, da formulação originária de novas apreensões do sentido. Como sintetiza M. Molano (2014), a abordagem conceitual benjaminiana sobre a experiência pode ser sintetizada em três dimensões: a) a recuperação da riqueza do sensorial, das capacidades expressivas e da vinculação emotiva com o real; b) o potencial mnemônico e espontâneo de atualizar a memória, na construção do sentido, em diálogo com as formas simbólicas incorporadas na linguagem; c) a reflexão crítica das formas de experiência acumuladas historicamente e respectivas relações de poder.

Se a cidade, em sua organização da sociedade capitalista, tende a impor formas pobres de experiência, cujo exemplo mais significativo será, porventura, a exposição das crianças aos fins de semana à sedução vazia dos corredores dos shoppings; se ela é, além do mais, pela restrição dos espaços e pela violência cotidiana, o locus da "produção de incivilidades" (ARAÚJO; CARVALHO, 2017), ela pode também ser o local da experiência infantil, pela potenciação das formas de descoberta e conhecimento que propicie. Pode sê-lo, seja por efeito da transgressão pelas crianças dos limites impostos pelas formas de condicionamento e restrição da circulação no ambiente, seja por políticas urbanas que favoreçam o desbravamento, pelas crianças, dos percursos físicos e simbólicos que se delineiam na cidade como espaço público e patrimônio coletivo, material e imaterial. A experiência da cidade pode ser estimulada pelos serviços educativos associados aos museus, pelo incentivo ao contato espontâneo com a natureza nos parques e jardins, pela abertura das ruas à circulação pedonal com segurança e às interações com os seus passeantes de todas as idades.

A possibilidade de interações intergeracionais é outra das potencialidades que as cidades oferecem às crianças. Numa sociedade dominada pelas lógicas produtivistas, a organização social do espaço-tempo limita o convívio no espaço público entre atores sociais de diferentes grupos de idade e estabelece regras de confinamento espacial por geração: as crianças passam a maior parte do seu tempo, quando não estão com a família, nos jardins de infância ou nas escolas; os idosos passam-no nos centros de dia, quando não mesmo nos lares de idosos onde estão institucionalizados; os adultos, nas empresas e nos serviços públicos onde trabalham. Mesmo as iniciativas culturais e recreativas são frequentemente realizadas para grupos geracionais específicos: espetáculos infantis, colônias de férias para crianças ou visitas guiadas a monumentos para os mais jovens, por um lado; programas de turismo sênior para idosos, universidades da terceira idade, caminhadas na natureza para os mais velhos, por outro.

A intergeracionalidade é uma possibilidade quando intencionalizada. Para que o corte entre gerações possa ser superado impõe a adoção de políticas públicas urbanas que garantam a abertura da cidade à participação de todos. O que implica o redesenho urbanístico das ruas e das praças, a criação de zonas livres de automóveis e a contínua abertura para a negociação da vida em comum na cidade (CHRISTENSEN; O'BRIEN 2003).

Com a participação social na cidade, fica garantida essa possibilidade de negociação.

Mesmo afastadas da ação política direta, nomeadamente pelo fato de estar interditada às crianças a possibilidade de, nas democracias liberais, serem agentes políticos ativos, isto é, poderem votar e serem eleitas para órgãos de representação, elas não deixam de ter opiniões e propostas para a vida na cidade.

Além de ser um direito consagrado na Convenção sobre os Direitos da Criança, a participação, no sentido preciso de possibilidade de apresentação da sua própria posição com influência na vida em comum, constitui um dos aspetos mais relevantes sinalizados no reconhecimento da cidadania ativa das crianças, nomeadamente no espaço urbano (SARMENTO; SOARES; TOMÁS, 2006; SARMENTO; FERNANDES; TOMÁS, 2007). Isso porque a cidade favorece relações de proximidade que tornam concretos os sentidos das propostas e posições das crianças sobre o espaço público. As crianças podem pronunciar-se sobre as diferentes dimensões da vida na cidade, da organização territorial e urbanística às questões de mobilidade, das agendas culturais às prioridades de investimento, do tipo de equipamentos ao desenho do mobiliário urbano. Se todos esses aspectos aparentam ter uma configuração técnica, que de fato possuem, as opções não deixam nunca de ser políticas e é sobre o sentido do bem comum que as crianças podem se pronunciar entre diferentes alternativas.

Além do mais, como a investigação sobre as práticas participativas das crianças no espaço urbano vem comprovando, as propostas das crianças estão sempre profundamente enraizadas na experiência corpórea do lugar. Isto é, exprimem uma posição original, frequentemente inesperada e alheia ao sentido mais comum das preocupações adultas, sem que por isso percam pertinência. A análise de experiências de participação, tal como as que são propostas em programas como os da Cidade das Crianças ou das Cidades Amigas das Crianças, já acima referidos - ou ainda no âmbito do projeto que se dirigiu na cidade de Guimarães, Portugal, de construção participativa da Carta da Cidadania Infantojuvenil (SARMENTO, 2016) -, permite comprovar que “[...] 
os conhecimentos locais e cotidianos que as pessoas mais novas adquirem através da mobilidade e interações nas suas comunidades são vitais para o desenvolvimento de infraestruturas sociais, físicas e culturais das respectivas comunidades" (CHRISTHENSEN et al., 2018, p. 147).

A participação das crianças não elimina a necessidade de proteção por parte dos adultos, nem se alcandora os mais novos ao estatuto de decisores políticos, fora da interação com os mais velhos. São úteis, por isso, os alertas contra interpretações simplistas da participação infantil (ARAÚJO, 2018). Esta resulta das dinâmicas de reconhecimento das crianças como atores sociais e sujeitos de cultura, não como meros reprodutores da ordem social e cultural adulta. Importa por isso garantir que a participação delas não seja o pretexto para formas de manipulação ou para a sua adultização precoce. A participação das crianças deve ela própria ser protegida. As políticas serão tanto mais adequadas quanto elas se orientarem para a construção de "contextos de participação" (TREVISAN, 2014), de adultos e de crianças, vitalizando a vida democrática e configurando o espaço urbano em torno de um sentido partilhado de bem comum.

É essa procura do bem comum no espaço público que, finalmente, a cidade pode potenciar, pela experiência da urbanidade pelas crianças, isto é, o sentido de uma participação na comunidade, a preocupação com o seu presente e com o seu futuro, o empenho em relações recíprocas de convivialidade e de sustentabilidade. Nessa dimensão de urbanidade, a infância se configura como geração com capacidade política: pela participação na vida em comum, as crianças apercebem-se das relações de poder e dos seus vínculos sociais, geracionais, de classe, de etnia e de gênero e, nesse contexto, confrontam-se com as suas próprias forças e com as suas fragilidades. Esse conhecimento é essencial à sua afirmação como cidadãs, seja no seu autorreconhecimento e na sua formação como tal, seja no reconhecimento pelos adultos do estatuto das crianças como membros ativos da sociedade, na sua especificidade geracional.

\section{Conclusão}

Como a cidade é o contexto de vida da grande maioria das crianças no mundo, é na cidade que se podem encontrar as condições da cidadania da infância.

No entanto, as cidades têm-se desenvolvido contemporaneamente com uma enorme complexidade, condicionando fortemente a vida dos seus habitantes, em consequência de fenômenos, como a divisão social do espaço; o incremento das desigualdades sociais com todos os seus efeitos; o aumento dos fluxos migratórios e a ausência de políticas autênticas de acolhimento dos imigrantes; a densificação do tráfego de automóvel; a exigência de novos equipamentos públicos e a sua carência ou insuficiência; as políticas predadoras do ambiente; a especulação imobiliária; a violência urbana; a dominação do espaço cultural e midiático pelos interesses da indústria cultural, proporcionando experiências pobres de fruição cultural.

Aparentemente, na relação entre infância e cidade, surgem obstáculos limitadores de uma plena afirmação dos direitos da criança.

No entanto, isso não é inelutável. Se as cidades, na sua organização espacial contemporânea, constrangem a vida das crianças, elas possuem, como aglomerado humano historicamente construído, potencialidades para que nelas se afirme o "direito à cidade". Para as crianças, o direito à cidade é a condição da sua própria cidadania, que não constitui uma proclamação jurídica nem é um estatuto outorgado. É, outrossim, algo que decorre diretamente de políticas públicas para a infância e para a cidade que garantam a participação de crianças e de adultos na edificação do território urbano, segundo lógicas de inclusão e sustentabilidade.

\section{REFERÊNCIAS}

ARAÚJO, Vania Carvalho de. Pensar a cidade, as crianças e sua educação. Educação (UFSM), v. 43, n. 2, abr./jun. 2018.

ARAÚJO, Vania Carvalho de; CARVALHO, José Sérgio Fonseca de. As possibilidades de uma experiência compartilhada entre adultos e crianças na cidade. Pro-Posições, v. 28, suppl.1, p. 111-131, 2017.

ARENHART, Deise. Culturas infantis e desigualdades sociais. Petrópolis: Vozes, 2016.

BARRA, Sandra Marlene Mendes. A infância na latitude zero: as brincadeiras da "criança global" africana. Tese (Doutoramento em Estudos da Criança) - Universidade do Minho, Braga, 2016.

BENJAMIN, Walter. Mythe et violence. Paris: Denoël, 1971.

CASTELLS, Manuel. The informational city. Oxford: Blackwell Castro, 1989.

CHRISTENSEN, Pia et al. Children living in sustainable built environments: new urbanisms, new citizens. London: Routledge, 2018.

CHRISTENSEN, Pia; O'BRIEN, Margaret (Ed.). Children in the city: home, neighbourhood and community. London: Routledge Falmer, 2003.

CORSARO, William A. The sociology of childhood. Thousand Oaks: Pine Forge Press, 1997.

FERREIRA, Maria Manuela. "A gente aqui o que gosta mais é de brincar com os outros meninos": as relações sociais num jardim da infância. Porto: Afrontamento, 2004.

FORTUNA, Carlos. Cidade, cultura e globalização. Oeiras: Celta, 1997. 
FUNDO DAS NAÇÕES UNIDAS PARA A INFÂNCIA (UNICEF). Crianças em um mundo urbano. New York: Unicef, 2012.

HARVEY, David. Social justice and the city. London: The University of Georgia Press, 2009.

HEFT, Harry. Affordances of children's environments: a functional approach to environmental description. Children's Environments Quarterly, v. 5, n. 3, p. 29-37, 1988.

JAMES, Allison; JENKS, Chris; PROUT, Alan. Theorizing childhood. Cambridge: Polity Press, 1998.

JENKS, Chris. Journeys into Space. Childhood, v. 12, n. 4, p. 419-424, 2005.

LE GALÈS, Patrick. Le retour des villes européennes: sociétés urbaines, mindialisation, gouvernement et gouvernance. Paris: Presses de Sciences PO, 2003.

LEFÈBVRE, Henri. O direito à cidade. São Paulo: Centauro, 2001.

LEVERETT, Stephen. Children spaces. In: FOLEY, R.; LEVERETT, S. (Ed.). Children and young people's spaces: developing practice. Basingstoke: Palgrave Macmillan, 2011.

LOPES, Frederico; CARLOS NETO. A criança e a cidade: a importância da (re)conciliação com a autonomia. In: CORDOVIL, R.; BARREIROS, J. (Ed.). Desenvolvimento motor na infância. Cruz Quebrada: Faculdade de Motricidade Humana, 2014. p. 265-292.

LOPES, João Teixeira. Andante, andante: tempo para andar e descobrir o espaço público. Sociologia, v. 17, n. 18, p. 69-80, 2007.

MARCHI, Rita de C. Os sentidos (paradoxais) da infância nas ciências sociais: um estudo de sociologia da infância crítica sobre a "não-criança" no Brasil. 2007. Tese (Doutorado em Sociologia Política) - Universidade Federal de Santa Catarina (UFSC), Florianópolis, 2007.

MOLANO, Mario Alejandro. Walter Benjamin: historia, experiencia y modernidade. Ideas y Valores, v. xiii, n. 154, p. 165-190, 2014.

O'BRIEN, Margaret; JONES, Deborah; SLOAN, David. Children's independent spatial mobility in the urban public realm. Childhood, v. 7, n. 3, p. 257-277, 2000.

PAIS, José Machado. Lufa-lufa quotidiana: ensaios sobre cidade, cultura e vida urbana. Lisboa: ICS, 2010.

SARMENTO, Manuel Jacinto. A reinvenção do ofício de aluno e de criança. Atos de Pesquisa em Educação, v. 6, n. 3, p. 581602, 2011.

SARMENTO, Manuel Jacinto. Carta da Cidadania Infantojuvenil do Conselho de Guimarães. Guimarães: ADCL, 2016. Disponivel em: $<$ http://www.adcl.org.pt/ccij/noticias/carta_da cidadania.pdf>. Acesso em: $1 \stackrel{0}{\circ}$ jul. 2018.
SARMENTO, Manuel Jacinto; FERNANDES, Natália; TOMÁS, Catarina. Políticas públicas e participação infantil. Revista Educação, Sociedade e Cultura, n. 25, p. 183-206, 2007.

SARMENTO, Manuel Jacinto; MARCHI, Rita; TREVISAN, Gabriela. Beyond the modern norm of childhood: children as the margins as a challenge for the sociology of childhood. In: BARALDI, C.; COCKBURN, T. (Ed.). Theorizing childhood: citizenship, rights and participation. Milton Keynes: PalgraveMacmillan, 2018. p. 135-157.

SARMENTO, Manuel Jacinto; SOARES, Natália Fernandes; TOMÁS, Catarina. Participação social e cidadania activa das crianças. In: RODRIGUES, David (Org.). Inclusão e educação: doze olhares sobre a educação inclusiva. São Paulo: Summus Editorial, 2006. p. 141-159.

SASSEN, Saskia. The global city: New York, London and Tokyo. Princeton: Princeton University Press, 2001.

SASSEN, Saskia. The city: its return as a lens for social theory. In: CALHOUN, C.; ROJEK C.; Turner, B. (Ed.). The sage handbook of sociology. London: Sage, 2005. p. 457-470.

SHAW, Ben et al. Children's independent mobility: an international comparison and recommendations for action. London: Policy Studies Institute, 2015.

SIROTA, Regine. Éléments pour une sociologie de l'enfance. Rennes: Presses Universitaires de Rennes, 2007.

TONUCCI, Francesco. La ciudad de los niños: un modo nuevo de pensar la ciudad. Madrid: Fund. German Sanchez Ruiperez, 1991.

TREVISAN, G. "Somos as pessoas que temos de escolher, não são as outras pessoas que escolhem por nós": infância e cenários de participação pública - uma análise sociológica dos modos de codecisão das crianças na escola e na cidade. 2014. Tese (Doutoramento em Estudos da Criança - Sociologia da Infância) - Universidade do Minho, Braga, 2014.

UNITED NATIONS CHILDREN'S FUND (UNICEF). Building friendly child cities. Florence: Unicef/Innocenti Research Centre, 2004.

WIEVIORKA, Michel. Nos enfants. Auxerre: Sciences Humaines Éditions, 2008.

ZEIHER, Helga. Shaping daily life in urban environments. In: CHRISTENSEN; O'BRIEN (Ed.). Children in the city: home, neighborhood and community. London: Routledge Falmer, 2003. p. 66-68.

Recebido em 04.06.2018

Aprovado em 09.07.2018

Endereço para correspondência:

Universidade do Minho - Portugal

Campus de Gualtar

4710-057 Braga 